\title{
Efeito da endogamia sobre pesos pré-desmame em bovinos da raça Nelore mocho criados a pasto no bioma Cerrado
}

\author{
Lopes, F.B. ${ }^{1}$; Magnabosco, C.U. ${ }^{2}$; Souza, F.M. de ${ }^{3}$; Assis, A.S. de ${ }^{3}$ e Brunes, L.C. ${ }^{\circledR}$
}

'College of Agricultural and Life Sciences. University of Wisconsin. Madison. USA.

${ }^{2}$ Embrapa Cerrados/CNPq. Planaltina. DF. Brasil.

${ }^{3}$ Programa de Pós-Graduação em Zootecnia. Escola de Veterinária de Zootecnia. Universidade Federal de Goiás. Goiânia. Goiás. Brasil.

\section{PALAVRAS CHAVE ADICIONAIS}

Consanguinidade.

Crescimento animal.

Habilidade maternal.

Melhoramento animal.

\section{ADDITIONAL KEYWORDS}

Animal growth.

Animal breeding.

Inbreeding.

Maternal ability.

\section{INFORMACIÓN}

\section{Cronología del artículo.}

Recibido/Received: 06.07.2015

Aceptado/Accepted: 01.03 .2016

On-line: 11.06 .2016

Correspondencia a los autores/Contact e-mail:

ludmillabrunes@hotmail.com

\section{RESUMO}

Objetivou-se com este trabalho analisar a tendência genética direta e maternal e estudar os efeitos da endogamia sobre pesos padronizados aos 120 (P120) e 210 (P210) dias de idade, em bovinos da raça Nelore pertencentes ao rebanho da Embrapa Cerrados. Os dados foram coletados no período de 1990 a 2010. Os valores genéticos foram preditos por soluções de equações de modelo animal. O coeficiente de endogamia foi calculado por meio do aplicativo MTDFREML. A matriz de parentesco incluiu 23513 animais, cuja estimativa média e máxima de endogamia foi 2,17 e 14,10\%, respectivamente. Porém, a média da endogamia do rebanho pode ser considerada baixa, quando comparada à de outros estudos. Os resultados indicaram que a endogamia direta provocou redução no mérito genético individual para os pesos padronizados aos 120 e 210 dias de idade, possivelmente, devido à redução na variância genética aditiva.

\section{Inbreeding effect on pre-weaning weight in polled Nellore cattle raised on pasture in the Cerrado biome}

\section{SUMMARY}

This study was carried out to estimate the genetic direct and maternal genetic trends and to study the inbreeding effect on the standardized weight at 120 (W120) and 210 (W210) days of age in polled Nellore cattle from Embrapa Cerrado herd. The records were collected between 1990 and 2010. Both breeding values and inbreeding coefficients were estimated using MTDFREML software. 23.513 animals were included in the relationship matrix. The mean and the maximum estimative of inbreeding coefficient were $2.17 \%$ and $14.10 \%$, respectively. Over the year there was genetic progress for genetic direct effect as well as for maternal effect. The average inbreeding of the herd can be considered low when compared with other studies. The results indicated direct inbreeding caused reduction in individual genetic merit for standardized weights at 120 and 210 days of age, possibly due to the reduction in additive genetic variance.

\section{INTRODUÇÃO}

Como forma de fixar características com maior intensidade e estabelecer as populações que serviriam de base para o melhoramento dos animais, os primeiros criatórios utilizaram a seleção endogamica (Carvalheiro e Pimentel, 2004). O acasalamento de animais aparentados promove o aumento do nível de homozigose, e em resultado disto, obtém-se indivíduos mais uniformes, por reduzir a variabilidade genética do rebanho (Kim et al., 2015).

Entretanto, a endogamia pode trazer problemas produtivos e reprodutivos ao rebanho, pois muitas anomalias congênitas se manifestam somente em ho- mozigose recessiva. Além disso, as chances de manifestação de combinações gênicas desfavoráveis são maiores entre animais endogâmicos, promovendo o efeito inverso da heterose, que resulta na depressão endogâmica (Carvalheiro e Pimentel, 2004; Gonçalves et al., 2011).

Estima-se que quando o coeficiente de endogamia ultrapassa valores de $10 \%$ há aumento significativo no número de lócus em homozigose, e consequentemente, aumento na chance de genes recessivos indesejáveis (Alcalá et al., 1995). Burrow (1998), em uma revisão de literatura, observou que para cada aumento de $1 \%$ no coeficiente de consanguinidade em bovinos, houve 
uma diminuição correspondente de 0,04, 0,72, 1,07, $1,49,2,07$ e $1,52 \mathrm{~kg}$ de peso vivo ao nascimento, 6 meses, 12 meses, 18 meses, 30 meses e 54 meses, respectivamente.

A utilização de técnicas reprodutivas, como inseminação artificial, ovulação múltipla e transferência de embriões, e a seleção massiva permitem maior contribuição de poucos indivíduos reprodutores nas gerações subsequentes. Isso possibilitou que os programas de melhoramento genético acelerassem o progresso genético e, também, se tornassem mais propensos ao aumento da endogamia (Carrilo e Siewerdt, 2010; Carvalheiro e Pimentel, 2004).

As raças zebuínas encontradas no Brasil tendem a apresentar baixa variabilidade genética, devido o pequeno número de animais fundadores e também às práticas de seleção aplicadas (Panetto et al., 2010). Malhado et al. (2008); Malhado et al. (2009) e Oliveira et al. (2011) observaram que o coeficiente de endogamia em populações da raça Nelore tem crescido ao longo dos anos, o que pode resultar em aumento do número de animais menos produtivos.

A inter-relação da estrutura populacional com progresso genético pode servir para nortear ações futuras, que permitirão o desenvolvimento de estratégias para o progresso genético da raça em determinada região (Malhado et al., 2008). Trabalhar estrategicamente com linhagens com grau de parentesco moderado pode auxiliar na impressão de características desejadas, mantendo o nível de consanguinidade dentro de uma margem de segurança, e assim evitar os efeitos deletérios que a endogamia pode trazer para o rebanho.

Sabendo que a endogamia tem consistente efeito sobre as características produtivas e que estas possuem expressiva parcela na remuneração do sistema produtivo é importante conhecer a relação entre os níveis de consanguinidade e o desempenho animal, para adoção de práticas que visam sempre maximizar a produtividade do rebanho. Além disso, os efeitos deletérios da consanguinidade podem ser mais pronunciada sob condições de estresse ambiental (Keller e Brinks, 1978). Isso leva a conclusão de que a relação entre níveis de consanguinidade e desempenho animal pode variar de região para região, assim como de sistema.

Destarte, objetivou-se com este trabalho analisar a tendência genética direta e maternal e estudar os efeitos da endogamia sobre pesos padronizados aos 120 e 210 dias de idade em bovinos da raça Nelore em condições do bioma Cerrado.

\section{MATERIAL E MÉTODOS}

Foram utilizados registros de animais da raça $\mathrm{Ne}-$ lore Mocho, provenientes de animais manejados em sistema extensivo de criação no Rebanho da Embrapa Cerrados, localizado no município de Planaltina, Distrito Federal. Os registros de pesos padronizados aos 120 e 210 dias de idade correspondem aos animais nascidos entre os anos de 1990 e 2010. O número de animais, média, desvio padrão e seus respectivos coeficientes de variação dos pesos padronizados aos $120 \mathrm{e}$ 210 dias de idade estão apresentados na tabela I.
Todas as análises estatísticas foram realizadas com o programa computacional Statistical Analysis System (SAS, 2002). As análises de variância foram realizadas com o procedimento General Linear Models (GLM), por intermédio do Método dos Quadrados Mínimos, de forma a verificar a influência de fatores não genéticos sobre as características em estudo. Foi considerado os efeitos fixos de grupos de contemporâneos (GC), os quais foram formados através da concatenação de fatores não genéticos que afetaram significativamente $(p<0,001)$ as características em estudo como rebanho, ano, estação de nascimento do animal agrupada em quadrimestre e sexo.

O coeficiente de endogamia foi calculado para cada animal e para o rebanho, de acordo com o método proposto por Wright (1923), utilizando-se o programa computacional MTDFNRM (Multiple Trait Derivative Free Numerator Relationship Matrix), que compõe o software MTDFREML, descrito por Boldman et al. (1995).

As análises de P120 e P210 foram realizadas segundo o modelo animal completo, a seguir:

$$
y=X \hat{a}+Z_{1} a+Z_{2} m+Z_{3} p+e
$$

em que,

y: vetor de observações (P120 e P210);

$\beta$ : vetor dos efeitos fixos (grupo de contemporâneos e idade da vaca ao parto, como co-variável);

$a$ : vetor do efeito genético aditivo direto;

$m=$ vetor de efeito genético aditivo maternal;

$p$ : vetor de efeitos de ambiente materno permanente;

$X$ : matriz de incidência que associa $\beta \operatorname{com} y$;

$Z_{1}, Z_{2}$ e $Z_{3}$ são matrizes de incidência do efeito genético direto, genético maternal e de ambiente permanente, respectivamente; $\mathrm{e}$,

$$
e=\text { vetor residual, } \mathrm{N} \sim\left(0, \sigma^{2}\right) \text {. }
$$

Os componentes de variâncias e covariâncias necessários à obtenção dos BLUP (Melhor Preditor Linear Não-Viesado) do mérito genético dos animais foram estimados pelo Método da Máxima Verossimilhança Restrita Livre de Derivadas (Smith e Graser, 1986), utilizando o aplicativo MTDFREML (Boldman et al., 1995).

O programa MTDFREML foi utilizado em três passos: no primeiro, tem-se a construção da inversa da matriz de parentesco e estimação dos coeficientes de endogamia; no segundo, a determinação do modelo animal; e, no terceiro passo, informou-se as estimativas iniciais dos componentes de (co) variâncias genéticas aditiva direta, maternal, de ambiente permanente maternal e residual. Os valores genéticos, para os efeitos genéticos aditivos diretos e maternais, para o P120 e P210 foram preditos a partir da solução das equações dos modelos mistos. As diferenças esperadas nas progênies (DEP) foram estimadas como metade do valor genético de cada animal. 
Tabela I. Número de animais, média, desvio padrão e coeficiente de variação dos pesos padronizados aos 120 (P120) e 210 (P210) dias de idade em bovinos da raça Nelore Mocho (Number of animals, mean, standard deviation and coefficient of variation for standardized weights at 120 (W120) and 210 (W210) days of age in polled Nellore cattle).

\begin{tabular}{lcccc}
\hline Característica & No $^{\circ}$ de animais & Média $(\mathrm{kg})$ & Desvio-padrão $(\mathrm{kg})$ & Coeficiente de variação $(\%)$ \\
\hline P120 & 941 & $120,25 \mathrm{~kg}$ & $17,84 \mathrm{~kg}$ & 14,86 \\
P210 & 853 & $181,70 \mathrm{~kg}$ & $27,02 \mathrm{~kg}$ & 14,87 \\
\hline
\end{tabular}
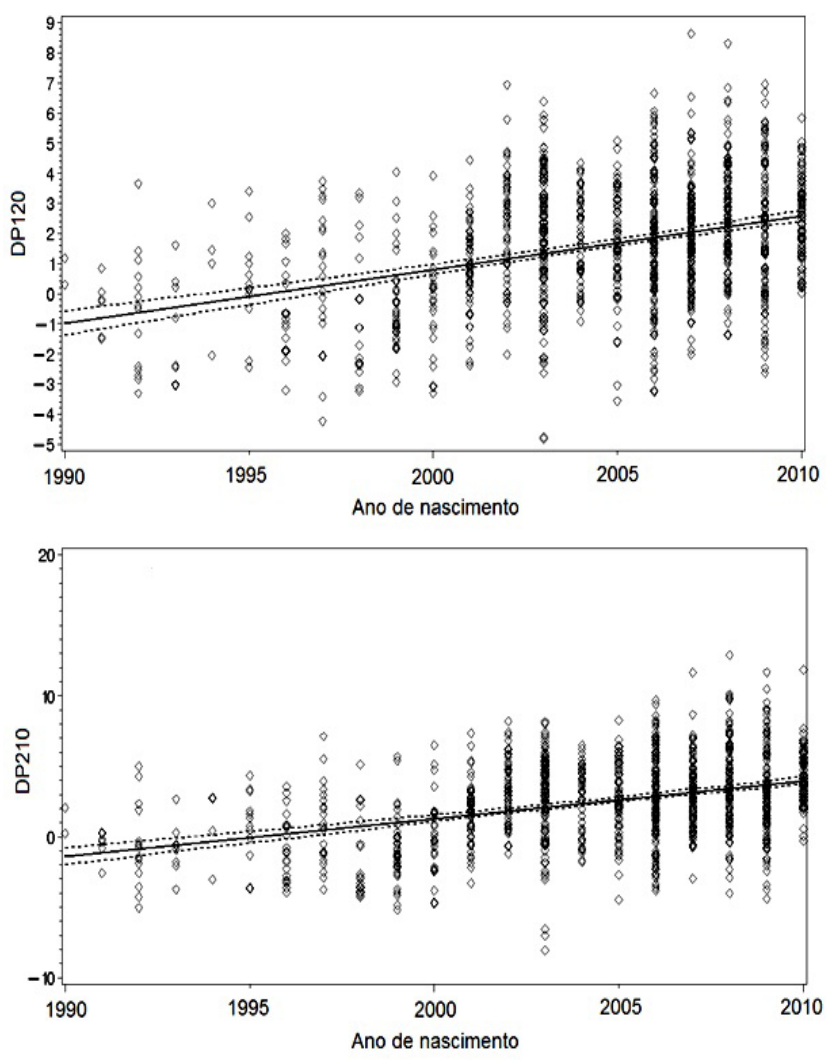

Figura 1. Tendência genética das DEPs (DP120 e DP210) do P120 e P210 em função do ano de nascimento do animal (Genetic trends of EPDs (EW120 and EW120) for W120 and W210 according to the year of birth of animal).

\section{RESULTADOS E DISCUSSÃO}

A média observada dos pesos ajustados aos 120 e 210 dias de idade (tabela I) nos animais pertencentes ao rebanho da Embrapa foram 120,25 $\pm 14,84$ e 181,70 $\pm 27,02 \mathrm{~kg}$, respectivamente. Estes resultados foram similares aos observados em animais da mesma raça provenientes de diferentes regiões do Brasil por Lira et al. (2013), Nepomuceno et al. (2013), Sena et al. (2013), inclusive a região Centro-oeste, conforme observado por Moreira et al. (2015).

A importância da obtenção do peso pré-desmame e ao desmame, para programas de seleção, está ligada a seu impacto econômico e na possibilidade de ser usado para a predição de pesos futuros. Além disso, é uma medida de produção anual da vaca de corte. Assim, serve para indicar sua habilidade materna, a qual é muito importante no sistema pecuário, pois os ganhos em peso alcançados a desmama apresentam custos inferiores aos obtidos em idades mais avançadas (Santos et al., 2012).
Os pesos pré e pós desmame são características importantes para acelerar a velocidade de crescimento, reduzindo o tempo para que o animal atinja o peso de abate, duração do ciclo de produção e, consequentemente, os custos de produção. $\mathrm{O}$ crescimento animal pode ser representado por uma curva sigmoide, compostas por quatro fases, sendo que a fase que se estende do nascimento a puberdade é a de crescimento mais acentuado, após este ponto, o crescimento tende a desacelerar (Santana, 2013). Este comportamento é explicado pelo fato de que até a puberdade, os ganhos de peso são representados, principalmente, por água, proteína e minerais direcionados para o crescimento ósseo e muscular. Ao atingir a puberdade, o crescimento muscular apresenta redução, enquanto há aumento da taxa de deposição de gordura (Freitas et al., 2000). A deposição de gordura é acompanhada pelo aumento das exigências de energia e de mantença (Carvalho et al., 2003), apresentando maiores exigências para ganho em peso (Freitas et al., 2006). Assim, a velocidade de ganho em peso do nascimento até a desmama é maior que no período subsequente, sendo uma fase onde há grande eficiência na utilização do alimento e, consequentemente, boa capacidade de discriminar os melhores animais pela seleção. Além disso, estudos demonstram que P120 e P210 apresentam herdabilidade por volta de 0,61 e 0,57, respectivamente (Lira et al., 2013, Sena et al., 2013). Logo a seleção dos melhores animais com base nas características pré-desmame poderá otimizar o sistema de criação de uma forma geral.

Na figura 1 estão apresentadas as análises da tendência dos efeitos genéticos aditivo direto do P120 e P210, sendo este crescente e de magnitude expressiva. As equações de regressão obtidas mostram que o incremento médio anual foi de $0,1789 \mathrm{~kg}$ e $0,2681 \mathrm{~kg}$ no valor genético aditivo do P120 e P210, respectivamente. Estes valores indicam que a seleção para peso nas idades analisadas foi eficiente e se reflete em progresso genético no rebanho. A importância aumenta considerando-se obter animais mais pesados ao desmame, pois, este fator vai influenciar nos pesos posteriores e também na obtenção de animais mais pesados em menores idades. Visto que, estudos demonstram, que a correlação entre pesos pré e pós-desmame podem chegar a 0,87 (Garnero et al., 2010).

As características da vida do animal que se expressam durante o período de amamentação, não são afetadas apenas pelo genótipo do animal (efeito aditivo direto), mas também pelo efeito da mãe (efeito aditivo materno) (Silva et al., 2015). Desta forma, o conhecimento do efeito maternal também é importante para contribuição no progresso genético dos P120 e P210. A seleção para DEPs de efeito genético aditivo maternal promoveu crescente ganho para as características de peso pré-desmame estudadas neste trabalho. Os valores 

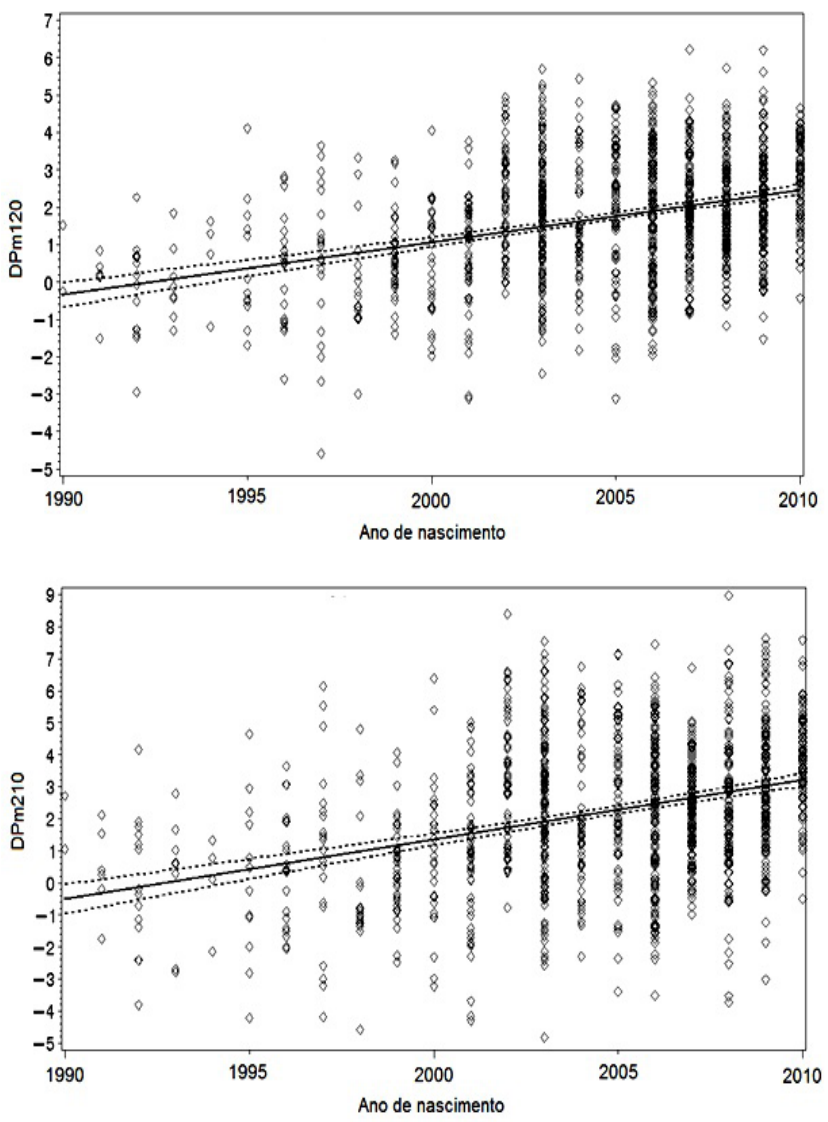

Figura 2. Tendência genética das DEPs maternais (DPm120 e DPm210) do P120 e P210 em função do ano de nascimento do animal (Genetic trends of maternal EPD (EWm120 e EWm210) for W120 and W210 according to the year of birth of animal).

de ganho genético referente ao efeito materno anual foram 0,140 e 0,186 $\mathrm{kg}$ para os respectivos pesos P120 e P210 (figura 2).

A análise das DEPs de efeito genético maternal (figura 2) mostraram que houve tendência crescente deste efeito da mesma forma que o efeito genético aditivo direto, o que pode ser explicado pela seleção conjunta dos melhores animais para ambos os efeitos (direto e maternal). Ressaltando-se, que a seleção combinada das características de efeito maternal e direto deve ser usada estrategicamente no rebanho, pois como se observa na literatura, a correlação entre estes efeitos é negativa (Souza et al., 2011). Com isso, em decorrência da seleção para efeito materno, o potencial inerente ao animal pode ser comprometido, e vice-versa. Apesar disso, ao longo do período avaliado a tendência positiva da regressão das DEPs (P120 e P210) direta e maternal demonstra que a seleção dos melhores animais com base nessas características tem sido eficiente no rebanho avaliado, refletindo na seleção de fêmeas com melhor habilidade materna. Esta característica está relacionada com a produção de leite e com o cuidado da mãe com a cria (Costa et al., 2008), fatores que vão corroborar com o desmame de animais em melhores condições, e consequentemente mais pesados.
Tabela II. Distribuição dos animais por classes de endogamia (Distribution of animals per classes of inbreeding coefficient).

\begin{tabular}{lc}
\hline Classe de endogamia & Número de animais \\
\hline $1-0,00$ & 932 \\
$2-0,00-0,01$ & 123 \\
$3-0,01-0,05$ & 74 \\
$4-0,05-0,09$ & 22 \\
$5->0,09$ & 11 \\
\hline Total & 1162 \\
\hline
\end{tabular}

Dos 23513 animais na matriz de parentesco, apenas 1162 pertenceram ao rebanho da Embrapa Cerrados. Do total de animais pertencentes a matriz de parentesco apenas 19,8\% apresentou certo grau de endogamia. Dentre os animais endogâmicos a estimativa de coeficiente de consanguinidade média e máxima foi de $2,17 \%$ e $14,10 \%$, respectivamente. Em torno de 5\% dos animais endogâmicos estavam acima de $9 \%$ do coeficiente de consanguinidade (tabela 2). Resultados semelhantes foram reportados por Garnero et al. (2008) e Malhado et al. (2010) em estudos avaliando animais da raça Nelore. Demonstrando que é comum observar rebanhos comerciais e de pesquisa, com baixos coeficientes de endogamia. Bem como, que

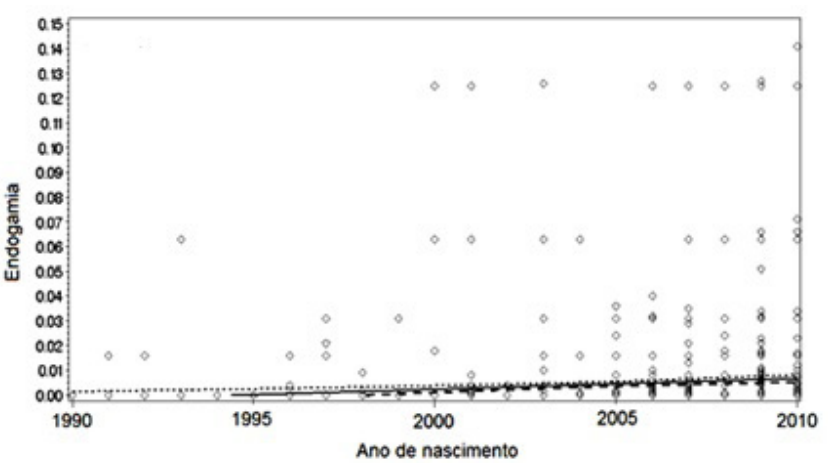

Figura 3. Regressão do percentual de endogamia em função do ano de nascimento dos animais (Regression of inbreeding rate by their year of birth of animals).

há uma tendência de os pecuaristas buscarem manter uma alta variabilidade genética dentro do rebanho. No presente estudo, não foi observado significativa quantidade de animais com coeficiente de consanguinidade comprometedor, pelo fato do rebanho da Embrapa estar sujeito ao controle de acasalamentos que restringe a endogamia abaixo de $10 \%$ (Alcalá et al., 1995).

Ao longo do período avaliado, embora de baixa magnitude, foi crescente o coeficiente de consanguinidade médio do rebanho (figura 3). Isto mostra a utilização dos mesmos ancestrais de forma mais intensa, possivelmente de genótipos superiores. A seleção de animais por meio de avaliação genética permite identificar animais superiores de forma mais precisa, e com isso ob- 
ter maior progresso genético. Contudo, a grande pressão de seleção faz com que um número restrito de animais seja utilizado como reprodutores e, com isso, o rebanho se torna mais susceptível ao aumento da endogamia. Além disso, conforme demonstrado por Queiroz et al. (2000), o aumento do coeficiente de endogamia, pode ser explicado pela estrutura do rebanho, que, com a evolução dos anos e realização de acasalamentos dentro do rebanho, ocorre aumento no grau de parentesco e também da endogamia entre os indivíduos.

A seleção genética por si só apenas tem efeito de isolamento do rebanho, pois seleciona sempre os melhores animais, dos quais teoricamente seus filhos serão superiores e sempre mantidos no rebanho, logo estes serão acasalados entre si promovendo o aumento da endogamia no rebanho, e consequente redução da variabilidade (Malhado et al., 2008). Por isso, o controle de acasalamento e a migração de genótipos diferentes, são ferramentas auxiliares na seleção com o objetivo de melhorar geneticamente os animais. De acordo com Falleiro et al. (2014) é possível manter a variabilidade genética do rebanho com níveis médios de endogamia em rebanhos com grande intensidade de seleção, mesmo apresentando uma população pequena.

Entretanto, quando não há controle de acasalamento, utilizando indiscriminadamente animais aparentados, o rebanho pode passar por depressão endogâmica, ocasionada pela diminuição da variabilidade genética
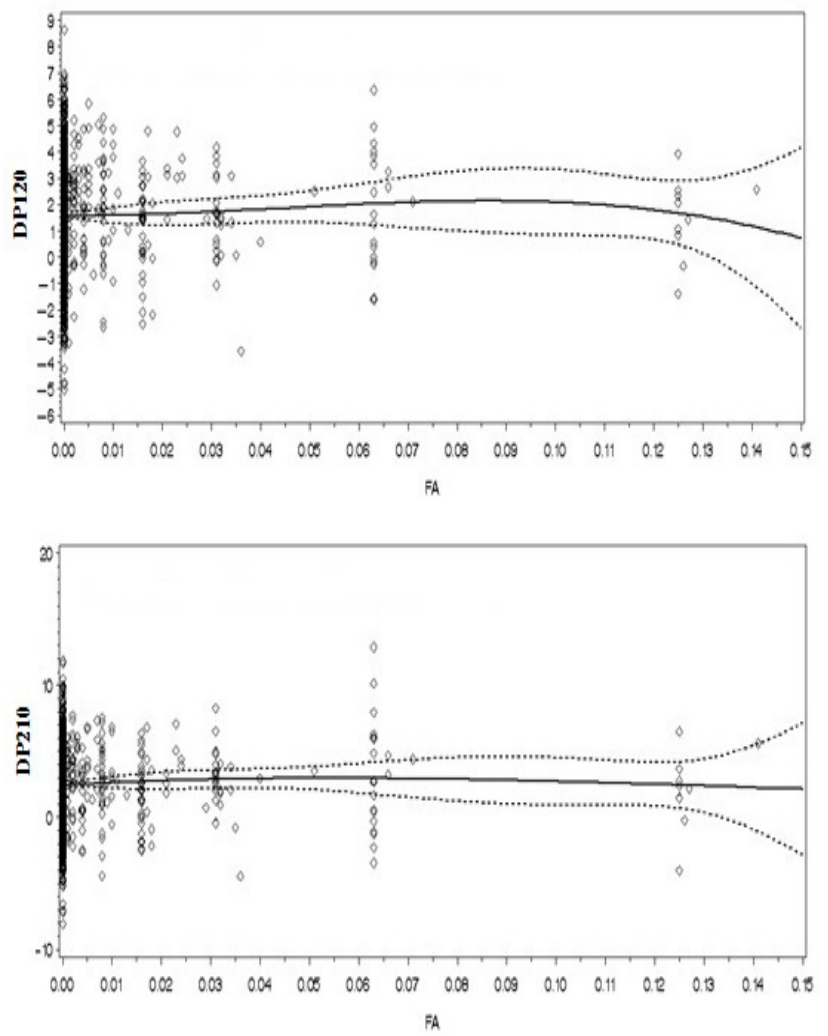

Figura 4. Efeito da endogamia (Fa) sobre as DEPs de pesos aos 120 (P120) e 210 (P210) dias de idade (Inbreeding (Fa) effects on EPDs for weights at 120 (W120) and 210 (W210) days of age). e aumento na homozigose, afetando negativamente o desempenho produtivo e reprodutivo dos bovinos (Ferenčaković et al., 2012). A redução do ganho genético e, consequentemente, do mérito genético em situações endogâmicas ocorrem porque, geralmente, os alelos com efeitos deletérios se manifestam em homozigose recessiva. Assim, a endogamia por si só não traria problemas a evolução do rebanho, se o aumento da homozigose ocorresse para alelos de efeitos favoráveis, porque ela aumenta a probabilidade de fixação desses alelos. Contudo, quando os alelos apresentam efeitos deletérios há redução da variância genética aditiva, da taxa de respostas e dos valores limites da seleção para as características alvo (Davis e Simmen, 2010).

No presente estudo, foi possível observar que valores de endogamia a partir de $8 \%$ de coeficiente de consanguinidade foram capazes de comprometer o P120 e o P210 dos animais avaliados (figura 4). Estes resultados corroboram com estudos já realizados (Carneiro et al., 2006; Santana et al., 2010), que afirmam que a endogamia pode resultar em menor desempenho animal.

Os produtores rurais dispõem de mais biotecnologias acessíveis, quando comparados às décadas passadas (Garnero et al., 2008), como por exemplo, uso de inseminação artificial e transferência de embriões que permitem a utilização intensiva de animais com maior valor genético, da mesma forma em que propiciam aumento de consanguinidade do rebanho. Portanto, os produtores devem conhecer o efeito depressivo da consanguinidade, com isso evitar sua prática deliberada.

Para otimizar o uso da variabilidade genética em populações de bovinos e assegurar maior resposta à seleção, minimizando os efeitos prejudiciais da endogamia, várias estratégias podem ser utilizadas, como prática de acasalamentos não aleatórios entre pais selecionados: acasalamentos do tipo fatorial (Sorensen et al., 2005); acasalamentos com parentesco mínimo (Colleau e Moreaux, 2006) e acasalamentos compensatórios (Kasarda et al., 2014).

\section{CONCLUSÃO}

Os valores do coeficiente de endogamia observados no rebanho em estudo são relativamente baixos. Ainda assim, o coeficiente de endogamia apresenta tendência crescente e influencia negativa no mérito genético para as características de peso aos 120 e 210 dias de idade. Dessa forma, faz-se necessário considerar os coeficientes de endogamia quando da efetivação dos acasalamentos, de forma a reduzir qualquer efeito relativo à depressão endogâmica.

\section{BIBLIOGRAFIA}

Alcalá, A.M.; Franganillo, A.R. y Córdoba, M.V. 1995. Analisis genético de los niveles de consaguinidad en la raza Retinta. Arch Latinoam Prod Anim, 44: 257-265. 
Boldman, K.G.; Kriese, L.A. e Van Vleck, L.D. 1995. A manual for use of MTDFREML.A set of programs to obtain estimates of variance and covariances [DRAFT]. Dejr. Lincoln. 120 pp.

Burrow, H.M. 1998. The effects of inbreeding on productive and adaptative trais and temperament of tropical beef cattle. Livest Produ Scie, 55: 227-243.

Carneiro, P.L.S.; Malhado, C.H.M.; Euclydes, R.F.; Torres, R.A.; Lopes, P.S.; Carneiro, A.P.S. e Cunha E.E. 2006. Oscilação genética em populações submetidas a métodos de seleção tradicionais e associados a marcadores moleculares. Rev Bras Zootecn, 35: 84-89.

Carrillo, J.A. and Siewerdt, F. 2010. Consequences of long - term inbreeding accumulation on preweaning traits in a closed nucleus Angus herd. J Anim Sci, 88: 87-95.

Carvalheiro, R. e Pimentel, E.C.G. 2004. Endogamia: possíveis consequências e formas de controle em programas de melhoramento de bovinos de corte. Workshop em genética e melhoramento na pecuária de corte. FCAV. UNESP. Jaboticabal.

Carvalho, P.A.; Bonnecarrère, L.M.; Pires, C.C.; Viégas, J.; Velho, J.P. e Paris, W. 2003. Composição corporal e exigências líquidas de proteína e energia para ganho de peso de bezerros machos de origem leiteira do nascimento aos 110 dias de idade. Rev Bras Zootecn, 32: 1484-1491.

Colleau, J.J. and Moureaux, S. 2006. Optimizing management of kinship and inbreeding coefficients in dairy cattle selection. INRA Prod Anim, 19: 3-14.

Costa, G.Z.; Queiroz, S.A.; Oliveira, J.A. e Fries, L.A. 2008. Estimativas de parâmetros genéticos e fenotípicos de escores visuais e de ganho médio de peso do nascimento a desmama de bovinos formadores da raça brangus. Ars Veterinaria, 24: 172-176.

Davis, M.E. and Simmen, R.C.M. 2010. Estimates of inbreeding depression for serum insulin-like growth factor I concentrations, body weights, and body weight gains in Angus beef cattle divergently selected for serum insulin-like growth factor I concentration. J Anim Sci, 88: 552-561.

Falleiro, V.B.; Malhado, C.H.M.; Malhado, A.C.M.; Carneiro, P.L.S.; Carrillo, J.A. and Song, J. 2014. Population structure and genetic variability of Angus and Nellore herds. J Agr Sci, 6: 276-285.

Ferenčaković, M.; Hamzic, E.; Gredler, B.; Solberg, T.R.; Emetsdal, G.; Curik, I. e Solkner, J. 2012. Estimates of autozygosity derived from runs of homozygosity: empirical evidence from selected cattle populations. J Anim Breed Genet, 130: 1-8.

Freitas, J.A.; Fontes, C.A.; Soares, J.E.; Jorge, A.M. e Estrada, L.H. 2000. Composição corporal e exigências de energia para mantença de bovinos (zebuínos e mestiços) e bubalinos não castrados, em confinamento. Arq Ciên Vet Zool, 3: 19-29.

Freitas, J.A.; Queiroz, A.C. de; Dutra, A.R.; Vieira, R.A.M.; Lana, R. de P.; Leonel, F. de P.; Henrique, D.S.; Lima, A.V. de e Souza, J.C. de. 2006. Composição do ganho e exigências de energia e proteína para ganho de peso em bovinos Nelore puros e mestiços. Rev Bras Zootecn, 35: 886-893.

Garnero, A.V.; Berruti, A.; Marcondes, C.R.; Martins, E.N.; Lôbo, R.B.; Araujo, R.O. e Gunski, R.J. 2008. Inbreeding in nucleous herds of Nellore cattle in Brazil. Livest Res Rural Develop, 20: 159.

Garnero, A. del V.; Muñoz, M.C.C.D.; Marcondes, C.R.; Lôbo, R.B.; Lira, T. e Gunski, R.J. 2010. Estimação de parâmetro genéticos entre pesos pré e pós-desmama na raça Nelore. Arch Zootec, 59: 1-4.

Gonçalves, R.W.; Costa, M.D.; Rocha Júnior, V.R.; Costa, M.R. da; Silva, E. de S.P. e Ribeiro Filha, A. de M. 2011. Efeito da endogamia sobre características reprodutivas em um rebanho da raça Mangalarga Marchador. Rev Bras Saúde Prod Anim, 12: 641-649.

Kasarda, R.; Mészáros, G.; Kladecík, O.; Hazuchová, E.; Sidlová, V. and Pavlík, I. 2014. Influence of mating systems and selection intensity on the extent of inbreeding and genetic gain in the Slovak Pinzgau cattle. Czech J Anim Sci, 59: 219-226.

Keller, D.G. e Brinks, J.S. 1978. Mating systems by environment interactions for weaning weight in Hereford cattle. J Anim Sci, 46: 54-59.

Kim, E.; Sonstegard, T.S.; Van Tessel, C.P.; Wiggans, G. and Rothschild, M.F. 2015. The relationship between runs of homozygosity and inbreeding in Jersey cattle under selection. Plos One, 10: 1-17.
Lira, T.S.; Pereira, L.S.; Lopes, F.B.; Ferreira, J.L.; Lôbo, R.B. e Santos, G.C.J. 2013. Tendências genéticas para características de crescimento em rebanhos nelore criados na região do trópico úmido do Brasil. $\mathrm{Ci}$ Anim Bras, 14: 23-31.

Malhado, C.H.M.; Carneiro, P.L.S.; Pereira, D.G. e Martins Filho, R. 2008. Progresso genético e estrutura populacional do rebanho Nelore no Estado da Bahia. Pesqui Agropecu Bras, 43: 1163-1169.

Malhado, C.H.M.; Carneiro, P.L.S.; Martins Filho, R. eAzevedo, D.M.M.R. 2009. Histórico genético e populacional do rebanho Nelore puro de origem no sertão nordestino. Pesqui Agropecu Bras, 44: 713-718.

Malhado, C.H.M.; Carneiro, P.L.S.; Malhado, A.C.M.; Filho, R.M.; Bozzi, R. and Ladle, R.J. 2010. Genetic improvement and population structure of the Nelore breed in Northern Brazil. Pesqui Agropecu Bras, 45: 1109-1116.

Moreira, H.L.; Canova, E.B.; Munari, D.P.; Bezerra, L.A.F.; Lobo, R.B. e $\mathrm{Paz}$, C.C.P. 2015. Parâmetros genéticos para período de gestação e características de crescimento pré e pós desmame em bovinos Nelore. $B$ Indústr Anim, 72: 130-135.

Nepomuceno, L.L.; Lira, T.S.; Lopes, F.B.; Lôbo, R.B.; Ferreira, J.L. 2013. Interação genótipo-ambiente para características sob efeito maternal na raça Nelore nos estados do Maranhão, Mato Grosso e Pará. Rev Bras Saúde Prod Anim, 14: 269-276.

Oliveira, P.S.; Santana Junior, M.L.; Pedrosa, V.B.; Oliveira, E.C. de M.; Eler, J.P. e Ferraz, J.B. 2011. Estrutura populacional de rebanho fechado da raça Nelore da linhagem Lemgruber. Pesqui Agropecu Bras, 46: 639-647.

Paneto, G.G. 2010. Análise de Polimorfismo do DNA mitocondrial em indivíduos residentes na grande São Paulo para aplicação na identificação humana. Tese (Doutorado em Biociências e Biotecnologia aplicadas à Farmácia). Universidade Estadual Paulista. Araraquara.

Queiroz, S.A. de; Albuquerque, L.G. de e Lanzoni, N.A. 2000. Efeito da endogamia sobre características de crescimento de bovinos da raça Gir no Brasil. Rev Bras Zootecn, 29:1014-1019.

Santana, T.J.S. 2013. Novos modelos de curvas de crescimento para bovinos de corte. Tese (Doutorado). Universidade Federal de Lavras. Lavras, 70 pp.

Santana Junior, M.L.; Oliveira, P.S.; Pedrosa, V.B.; Eler, J.P.; Groeneveld, E. and Ferraz, J.B.S. 2010. Effect of inbreending on growth and reproductive traits of Nellore cattle in Brazil. Livest Sci, 131: 212-217.

Santos, G.C. de J.; Lopes, F.B.; Marques, E.G.; Silva, M.C.; Cavalcante, T.V. e Ferreira, J.L. 2012. Tendência genética para pesos padronizados aos 205, 365 e 550 dias de idade de bovinos Nelore da região norte do Brasil. Acta Scie Anim Sci, 34: 97-101.

SAS Institute Inc. 2002. Statistical Analysis System user's guide. Version 9.0 ed. SAS Institute. Cary. USA.

Silva, J.A. II de V.R.; Ribeiro, C.B.; Maiorano, A.M.; Hadlich, J.C.; Curi, R.A.; Oliveira, H.N.; Lamare, M. e Meirelles, P.R. de L. 2015. Influência de fatores ambientais sobre pesos pré-desmama de bovinos cruzados Aberdeen Angus x Nelore. Rev Bras Saúde Prod Anim, 16: 278-289.

Souza, J.C.; Silva, L.O.C.; Gondo, A.; Freitas, J.A.; Malhado, C.H.M.; Filho, P.B.F.; Sereno, J.R.B.; Weaber, R.L. e Lamberson, W.R. 2011. Parâmetros e tendência genética de peso de bovinos criados á pasto no Brasil. Arch Zootec, 60: 231.

Smith, S.P. and Graser, H.U. 1986. Estimating variance components in a class of mixed models by restricted maximum likelihood. J Dairy Sci, 69: 1156-1165.

Sena, J.S.S.; Matos, A. de S.; Marcondes, C.R.; Bezerra, L.A.F. e Lôbo, R.B. 2013. Parâmetros genéticos, tendências e resposta à seleção de características produtivas da raça Nelore na Amazônia Legal. Atas de Saude Amb, 1: 3-12.

Sorensen, A.C.; Berg, P. and Woolliams, J.A. 2005. The advantage of factorial mating under selection is uncovered by deterministically predicted rates of inbreeding. Genetics Sel Evol, 37: 57-81.

Wright, S. 1923. Mendelian analysis of pure breeds of livestock. I - The measurement of inbreeding and relationship. J Hered, 14: 339-348. 